\title{
Teoria e Evidências do Regime de Metas Inflacionárias
}

\author{
Theory and Evidence of the \\ Inflationary Targets Regime
}

JOÃO SICSÚ*,***

\begin{abstract}
RESUMO: Este artigo mostra que a teoria que apoia o regime de metas de inflação não tem relação com a realidade. Além disso, isso enfatiza que a política monetária deve ser usada com capacidade total, porque não apenas controla a inflação, mas também é útil para alcançar objetivos reais, como o emprego. $\mathrm{O}$ artigo demonstra que não há evidências de que o regime tenha reduzido a inflação na década de 90 . Tanto os países desenvolvidos que adotaram o regime como os países desenvolvidos que não adotaram o regime de metas para a inflação reduziram e mantiveram a inflação sob controle.

PALAVRAS-CHAVE: Bancos centrais; meta de inflação; política monetária.
\end{abstract}

ABSTRACT: This article shows that the theory that supports the inflation targeting regime does not have a relationship with reality. Moreover, this stresses that monetary policy should be used to full capacity because it not only controls inflation, but is also useful to achieve real goals, such as employment. The article shows that there is no evidence that the regime reduced inflation in the 1990's. Developed countries which adopted the regime and developed countries which did not adopt inflation targeting regime have both reduced and kept inflation under control.

KEYWORDS: Central banks; inflation target; monetary policy.

JEL Classification: E31; E43; E52; E58.

\footnotetext{
* Professor Adjunto do Departamento de Economia da Universidade Federal Fluminense (UFF). E-mail: joaosicsu@gmail.com; Orcid: 0000-0003-3997-7129.

** O autor agradece a leitura e comentários feitos por Gilberto Tadeu Lima, Fernando Ferrari e por um parecerista anônimo. O autor é, ainda, profundamente grato à FAPERJ e ao CNPq, pelo apoio. A coleta dos dados e a elaboração dos gráficos foi feita por Manoel Carlos de Castro Pires, graduando do Departamento de Economia da Universidade Federal Fluminense e integrante do Pibic/CNPq.
} 


\section{INTRODUÇÃO}

Nova Zelândia, Canadá, Reino Unido, Suécia, Finlândia, Austrália e Espanha foram os países desenvolvidos que nos últimos anos adotaram o regime de metas inflacionárias. O Brasil aderiu ao mesmo regime no ano de 1999. Tal regime propõe uma meta de crescimento para algum índice de inflação, que é anunciada no início de um determinado período. A meta é estabelecida pelo governo e/ou parlamento e deve ser perseguida pelo banco central, cuja política monetária passa a ter um único objetivo: alcançar a meta inflacionária determinada. Assim, os dirigentes do banco central não devem se preocupar com o desempenho de outras variáveis macroeconômicas. Por exemplo, o desemprego e o produto de uma economia somente se tornariam objeto de análise se estivessem dificultando a realização da meta de inflação, que é o alvo exclusivo do banco central.

No Brasil, as metas são anunciadas pelo Conselho Monetário Nacional (CMN). que é presidido pelo ministro da Fazenda, Pedro Malan. O índice escolhido foi o IPCA calculado pelo IBGE. Para o ano de 1999, a inflação estabelecida foi de $8 \%$ com tolerância de $2 \%$ para cima ou para baixo, isto é, foi estabelecida uma metaintervalo de 6 a $10 \%$. Para o ano 2000, foi fixada uma meta-intervalo de 4 a $8 \%$, e para o ano 2001 foi anunciada uma meta entre 2 e $6 \%$. Em junho de 2000, o CMN estabeleceu a meta para 2002 , que será $3,5 \%$ com intervalo de $2 \%$, para cima ou para baixo. O governo delegou as decisões de política monetária e a responsabilidade pelo cumprimento das metas aos dirigentes do Banco Central (Bacen). Caso a meta não seja atingida, o presidente do Bacen terá que enviar uma carta (que deve ser de conhecimento público) ao ministro da Fazenda justificando as razões do fracasso. Em tese, o não-cumprimento da meta pode provocar até mesmo a demissão do presidente do Bacen e da sua diretoria.

Mostra-se neste artigo que a teoria que sustenta o regime de metas inflacionárias não é consensual entre os economistas e, por último e mais importante, que suas hipóteses não possuem evidências capazes de sustentá-las. Por vezes, tais hipóteses nem mesmo possuem consistência interna. Ademais, argumenta-se que a política monetária não deve ser subutilizada, tendo somente um objetivo, o controle da inflação. A política monetária é útil também para fins reais, isto é, para estimular o produto e o emprego de uma economia. Busca-se, ainda, mostrar que não existem evidências de que o regime de metas seja o responsável pela boa performance da inflação nos últimos anos. Para tanto, mostra-se que países que adotaram o regime de metas inflacionárias e países que não o adotam, ambos os conjuntos, têm tido sucesso no front da inflação.

\section{METAS INFLACIONÁRIAS E TEORIAS MONETÁRIAS}

Os defensores da adoção de metas de inflação acreditam que a política monetária não é um instrumento que pode estimular o investimento e, conseqüentemente, reduzir o desemprego. Apóiam suas crenças na hipótese da existência da taxa 
natural de desemprego, na curva-expectacional de Phillips e no chamado viés inflacionário. Postulam que uma política monetária que aumente a liquidez da economia (e/ou reduza os juros) objetivando estimular o crescimento somente pode causar efeitos reais passageiros e efeitos inflacionários permanentes - tal como defendem Robert Lucas, Robert Barro e David Gordon em inúmeros trabalhos. Alguns, como Finn Kydland e Edward Prescott (1994), consideram que nem sequer efeitos passageiros seriam produzidos, somente inflação seria gerada. Assim sendo, a política monetária não deve ser utilizada para apoiar o crescimento econômico de um país. Caso uma política monetária ativista fosse implementada, estaria verdadeiramente sendo inócua a curto termo e, adicionalmente, estaria dificultando o crescimento no longo termo, pois estaria gerando um ambiente de inflação.

Mais ainda, os defensores do regime de metas consideram que ministros, parlamentares e empresários possuem uma feroz propensão a gerar inflação (o que chamam de viés inflacionário), já que tais segmentos clamam, permanentemente, por reduções das taxas de juros e por políticas de crédito-fácil. Então, o regime de metas proposto é coerente com suas crenças: um banco central deve tentar apenas controlar a inflação porque a política monetária não pode fazer nada além disso. E metas devem ser fixadas porque se transformam em um eficaz remédio contra o vírus (ou viés) inflacionário que acomete ministros, parlamentares, empresários e, por fim, policy-makers.

Em verdade, os defensores da adoção de metas inflacionárias acreditam em teorias monetárias que não são e nunca foram consensuais entre os economistas. Nos últimos anos, o número de economistas adversários do tripé - taxa natural de desemprego, viés inflacionário e curva-expectacional de Phillips - aumentou. John Maynard Keynes, um dos maiores economistas do século XX, Robert Eisner, ex-presidente da Associação Americana de Economia, William Vickrey e James Tobin, laureados com Prêmio Nobel, entre outros tão renomados economistas, nunca aceitaram tais teorias monetárias. Grosso modo, a teoria econômica iniciada por Keynes nos anos 1920/30/40 sempre pregou que uma redução da taxa de juros de longo termo poderia estimular o investimento produtivo porque desestimularia $o$ investimento financeiro.

Aos olhos de Keynes, os resultados que poderiam ser obtidos por uma redução da taxa de juros seriam duradouros. Mais fábricas, por exemplo, seriam abertas e parte daqueles que estavam involuntariamente desempregados encontrariam trabalho. A política monetária poderia, dessa forma, estimular o crescimento econômico. A redução do desemprego, portanto, também deve ser um objetivo da polí-

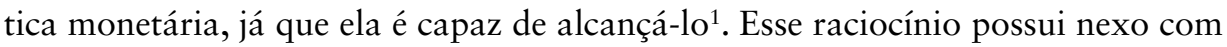
a realidade, explicaria por que ministros, empresários e parlamentares desejam sempre uma redução da taxa de juros em situações de desaquecimento econômico. Se políticas monetárias expansionistas inevitavelmente sempre gerassem, ao fim e

\footnotetext{
${ }^{1}$ Detalhes sobre a necessidade de intervenção do Estado na economia, as possibilidades de intervenção e o padrão de intervenção sugerido por Keynes podem ser encontrados em Cardim de Carvalho (1999).
} 
ao cabo, somente inflação, isso já teria sido aprendido por esses segmentos que não clamariam por algo que seria considerado ineficaz e prejudicial. Seria ineficaz porque não estimularia o investimento-real e a abertura de novos postos de trabalho. Seria prejudicial porque produziria inflação. Acreditar em viés inflacionário de empresários é desconsiderar que o que desejam verdadeiramente é o crescimento econômico que amplia o leque de possibilidades de obtenção de lucro. Acreditar em viés inflacionário de ministros e parlamentares é considerá-los em sua totalidade como irresponsáveis, seria o mesmo que avaliar que sempre estariam dispostos a trocar a situação corrente de estabilidade por benefícios de curto termo e instabilidades de longo termo.

Persson \& Tabellini (1994, p. 7), dois autores que acreditam na existência do vírus inflacionário, afirmaram que, muito embora todo o arcabouço teórico do mainstream que sustenta a problemática da política monetária seja impecável, não é possível observar taxas de inflação consideráveis em todos os países e em todos os tempos como decorrência do viés inflacionário. Justificaram esse incômodo imposto pela realidade, aduzindo que "a razão pela qual observamos taxas de inflação relativamente baixas [...] deve ser que sociedades têm a capacidade para desenvolver alguns mecanismos que minoram os incentivos [inflacionistas] [...]” (pp. 78). Contudo, tal justificativa parece extremamente frágil. Assim, a questão não é se uma economia possui (ou não) viés inflacionário e se possui (ou não) mecanismos para contê-lo, mas apenas se uma economia tem (ou não) inflação: se existem taxas de inflação consideráveis é porque o viés inflacionário não é contido por mecanismos eficazes, se tais taxas inexistem é porque o contrário vigora. Mas quais são esses mecanismos? Essa é a questão central! Diante dessa pergunta, os autores apenas afirmaram que "torna-se interessante estudar quais são exatamente esses mecanismos, particularmente porque [...] a eficiência desses mecanismos parece variar através dos tempos e das sociedades” (1994, p. 8). Em síntese, as desculpas de Persson \& Tabellini (em relação à percepção de que existem economias em que o viés inflacionário não se manifesta) levam apenas ao lugar comum, isto é, algo existe em certas economias que explica a ocorrência de taxas de inflação bastante baixas.

A taxa natural de desemprego, a teoria da curva de Phillips e o viés inflacionário, que são os principais pilares da teoria ortodoxa da política monetária, têm sido questionados no interior da profissão. São conhecidas as veementes críticas de Hahn (1984) à existência de uma taxa natural de desemprego. Não há também evidências, amplamente aceitas pelos economistas, de que a taxa natural de desemprego e a teoria da curva-expectacional de Phillips, que sustentam a proposição das metas inflacionárias, tenham a capacidade de explicar a realidade. $\mathrm{O}$ mundo real está há algum tempo contradizendo as previsões decorrentes dessas teorias, mesmo em suas versões mais modernas. No meio da década de 1990, os defensores da curva-expectacional de Phillips e da taxa natural de desemprego afirmavam convictos que uma taxa de desemprego inferior a $6 \%$ nos Estados Unidos desencadearia um processo inflacionário. Desde então, a taxa de desemprego se reduziu. 
Estacionou em patamares inferiores a $6 \%$ e não provocou qualquer inflação significativa.

Ao invés de inflação, foram as tendências deflacionárias (decorrentes da desaceleração do ritmo de crescimento das principais economias e dos ganhos de produtividade proporcionados pelos imensos avanços tecnológicos), durante os anos 1990, que ressurgiram em grande parte do mundo. Tal evento não foi previsto pelos economistas adeptos da taxa natural de desemprego, do viés inflacionário e da curva-expectacional de Phillips. Muito pelo contrário, enquanto estavam elaborando mecanismos antiinflacionários que objetivam manter as economias semidesaquecidas, o que diversos países estavam demandando eram políticas monetárias antidesemprego.

Por terem contestado o suposto consenso teórico estabelecido pelo mainstream da ciência econômica, Keynes e seus seguidores têm sido injustamente acusados de serem condescendentes com a inflação e unicamente de se preocuparem com o desemprego. Para afastar essa pecha, Keynes afirmou, no seu magnífico livro Essays in Persuasion, que a inflação é injusta e a recessão é inconveniente e, então, concluiu: “entretanto, não é necessário compararmos um mal com o outro. É necessário reconhecer que ambos são males que devem ser evitados" (1972: 15). Tobin, com o mesmo intuito de Keynes, no seu Essays in Economics, escreveu: "tenho argumentado que as autoridades monetárias não deveriam, em verdade, não podem fugir da responsabilidade por resultados macroeconômicos reais. Para evitar mal entendido, afirmo com toda clareza que não estou advogando que não se preocupem com [...] a inflação" (1996: 478).

Pode-se dizer que, no momento, a grande lição em termos de condução da política monetária tem sido dada pelo experiente Alan Greenspan, que sabe muito bem para que serve a política monetária: ele promoveu, embora tardiamente, cortes profundos na taxa de juros da economia americana (de 5,50 para 4,75\%, durante o outono de 1998, hemisfério norte) para evitar que o seu país viesse a ser atingido pela onda mundial de desaquecimento e desemprego - e, recentemente, elevou a taxa de juros sinalizando que está disposto a combater pressões inflacionárias advindas, principalmente, do mercado de trabalho.

Governos responsáveis devem entender que as decisões de política monetária não devem pertencer exclusivamente aos dirigentes do banco central. Um governo que aceita abrir mão da sua política monetária antidesemprego está, no mínimo, sendo mal-orientado. Mas é dessa forma que o governo brasileiro vem tratando a política monetária. Não tem havido aparentemente qualquer articulação do ministro da Fazenda com o presidente do Banco Central para decidir o patamar dos juros. As palavras de Armínio Fraga são reveladores dessa falta de articulação: "desde que eu vim para cá [o Bacen], nunca recebi (do ministro da Fazenda ou presidente da República) um telefonema sequer com relação às decisões do Copom (que definem o nível da taxa de juros)" (Gazeta Mercantil, 14/5/1999).

A política monetária é uma das políticas econômicas governamentais que devem ser utilizadas conjuntamente com as demais políticas para se atingir níveis socialmente aceitáveis (e tecnicamente sustentáveis) de emprego e inflação. Uma 
política monetária voltada somente para manter a inflação sob controle está, na verdade, sendo sub-utilizada. Mas assim está sendo (e será) comandada a política monetária no Brasil, tal como afirmou o diretor de política econômica do Banco Central: "vamos mirar só a inflação, não temos objetivo de olhar a atividade econômica" (Gazeta Mercantil, 29/6/1999). O que ele quis dizer, na verdade, é que o Bacen não vai manipular os juros para facilitar taxas de crescimento do PIB ou a geração de empregos.

\section{EVIDÊNCIAS INTERNACIONAIS}

Argumentos empíricos também têm sido utilizados na defesa do regime de metas inflacionárias. É comum se ouvir dizer que o regime de metas tem sido bem-sucedido nos países onde passou a ser adotado. Realmente, deve-se reconhecer que a inflação assumiu uma trajetória descendente durante os últimos anos nos sete países desenvolvidos que adotaram o novo regime. A Nova Zelândia, em 1990, foi o primeiro país a implementar o regime de metas, depois veio o Canadá, em 1991, o Reino Unido, em 1992, a Suécia, a Finlândia e a Austrália, em 1993 e, por último, a Espanha, em 1994. Como mostram os gráficos 1 a 7, a inflação desse conjunto de países manteve a sua rota descendente após a implementação do novo regime comparativamente à década anterior.

Entretanto, é importante ser destacado que o regime de metas não foi o responsável pela imposição da trajetória descendente da variação do nível de preços nesses países. Com exceção do Canadá (como pode ser observado nos gráficos $1 \mathrm{a}$ 7), todos os demais países já possuíam uma trajetória descendente da inflação que é anterior a implantação do regime de metas cujo início está marcado em cada gráfico. Minskin \& Posen (1997: 87-8), dois dos maiores defensores do novo regime, em um estudo sobre as três primeiras economias que adotaram as metas de inflação (Nova Zelândia, Canadá e Reino Unido), concluíram que a redução da inflação nesses três países foi resultado das forças que já estavam em movimento antes da adoção das metas. Os autores reconheceram que "na Nova Zelândia, ocorria uma desinflação há quatro anos anteriormente à implementação das metas que foi acompanhada de um lento crescimento do PIB e, desde 1988, crescimento do desemprego" (1997: 87). Para os autores, o Canadá e o Reino Unido também enfrentavam cenários de desaquecimento econômico durante o período de adoção das metas.

Minskin \& Posen afirmam somente que o novo regime é o responsável pela manutenção das taxas inflacionárias em patamares aceitáveis. Mas até mesmo essa tímida conclusão não parece plausível, porque todos os demais países com economias desenvolvidas que não possuem metas de inflação também têm mantido suas taxas em níveis aceitáveis, tal como é mostrado a seguir.

A despeito das evidências indicadas nos gráficos 1 a 7 , não existem argumentos suficientemente sólidos que garantam que a adoção de metas inflacionárias seja a responsável pela queda da inflação. Países que adotaram o regime de metas e países 
que não adotaram têm tido sucesso no front da inflação. O gráfico 8 mostra a trajetória da inflação média dos demais países com economias desenvolvidas que não adotaram o regime de metas de inflação, que são: Estados Unidos, Japão, Noruega, Dinamarca, Bélgica, Holanda, Áustria e Portugal. Cada ponto do gráfico corresponde à taxa de inflação de um determinado país em determinado ano. A inflação desse conjunto de países também apresentou uma tendência de queda durante a década de 1990 relativamente à década de $1980^{2}$, tal como os países que possuem metas de inflação. A explicação para esse fato foi dada por Andrew Haldane, do Banco Central da Inglaterra e um dos maiores defensores da adoção de metas inflacionárias:

metas de inflação têm sido propostas durante um período em que as pressões inflacionárias são benignas em comparação com os anos 1970/80. Quanto da melhora na performance da inflação nos anos 1990 pode ser atribuído à boa sorte e quanto se pode atribuir à boa administração monetária permanece como uma questão aberta, em países com ou sem metas de inflação. (1995: 11)

Haldane concluiu sua avaliação afirmando que não se pode ainda saber se o regime de metas se transformará em uma caminhada segura ou perigosa durante a próxima década. A onda mundial dos anos 1990 foi de desaquecimento econômico e de desaceleração das taxas inflacionárias (isto sim, é um consenso entre os economistas e não a teoria que sustenta o regime de metas inflacionárias).

Os resultados apresentados na tabela 1 , a seguir, reforçam o argumento de que o regime de metas não pode explicar a boa performance da inflação nos países desenvolvidos nos anos 1990. A inflação anual média nos países com metas de inflação no período $1990-98$ foi de $3,4 \%$ e nos países que não possuem metas foi de $3,2 \%$ (uma diferença que não pode ser considerada significativa). A mesma tabela mostra também que não é evidente que o regime de metas tenha criado um cenário macroeconômico mais favorável ao crescimento nos anos 1990. Os países que não adotaram o regime de metas tiveram um crescimento médio anual do PIB semelhante aos países que adotaram o regime. Enquanto os primeiros cresceram em média ao ano $2,5 \%$, os outros, cresceram $2,7 \%$.

\footnotetext{
${ }^{2}$ França, Itália, Suíça e Alemanha possuem somente alguns elementos do regime de metas de inflação. Podem ser considerados um grupo intermediário entre aqueles países que aparecem nos gráficos 1 a 7 e os do gráfico 8. Fez-se a opção por não inseri-los na presente comparação. Cabe, no entanto, destacar que suas trajetórias de inflação são bastante semelhantes àquelas dos dois grupos de países estudados.
} 
Tabela 1: Taxa de Inflação e Variação do PIB nos Países Desenvolvidos, 1990-1998

\begin{tabular}{lcc}
\hline \multicolumn{1}{c}{ Países Desenvolvidos } & $\begin{array}{c}\text { Taxa de Inflação } \\
\text { Anual Média (\%) }\end{array}$ & $\begin{array}{c}\text { Variação Anual } \\
\text { Média do PIB (\%) }\end{array}$ \\
\hline Austrália & 3,0 & 2,9 \\
Canadá & 2,4 & 1,9 \\
Espanha & 4,8 & 3,0 \\
Finlândia & 2,5 & 1,9 \\
Nova Zelândia & 2,8 & 2,4 \\
Reino Unido (1) (2) & 4,5 & 4,2 \\
Suécia & 4,2 & 1,5 \\
\hline Média dos Países & 3,4 & 2,5 \\
\hline Países Desenvolvidos & Taxa de Inflação & Variação Anual \\
Sem Metas de Inflação & Anual Média (\%) & Média do PIB (\%) \\
\hline Áustria & 2,7 & 2,7 \\
Bélgica & 2,5 & 2,2 \\
Dinamarca & 2,2 & 2,8 \\
Estados Unidos & 3,3 & 2,4 \\
Holanda & 2,7 & 2,8 \\
Japão & 1,4 & 1,9 \\
Noruega & 2,8 & 2,3 \\
Portugal (3) & 3,3 & \\
\hline Média dos Países & 3,6 \\
\hline Fon & 2,3 \\
\hline
\end{tabular}

Fonte: Fundo Monetário Internacional

(1) média da inflação calculada para o período 1990-97; (2) média do PIB calculada para o período 1990-96; (3) média do PIB calculada para o período 1990-97

Não se pode afirmar, então, que o regime de metas seja o responsável pela boa performance da variável nível de preços ou pelo ritmo de crescimento das economias desenvolvidas que adotaram esse regime durante anos 1990.

\section{SUMÁRIO E CONCLUSÕES}

O debate sobre uma decisão tão importante, a implementação de um regime de metas de inflação, não foi suficiente no Brasil. Não confrontou teorias divergentes e se pautou apenas pela discussão sobre a operacionalidade da fixação de metas. Quando argumentos teóricos foram ressaltados, foram tratados como verdades indisputáveis. Por exemplo, foi dito que o sistema de preços necessita inevitavelmente de algum tipo de âncora. Afirmaram que, na prática, somente existem duas âncoras: a cambial e as metas de inflação (Armínio Fraga, Gazeta Mercantil, 
29/6/1999). Como a primeira é considerada insustentável nos tempos da globalização dos mercados de câmbio, restou a segunda.

Esse argumento, contudo, é falacioso. Nem mesmo todos os economistas que acreditam na existência da taxa natural de desemprego e na curva de Phillips aceitariam tal afirmativa. Milton Friedman (1987), por exemplo, está entre aqueles que condenam explicitamente a fixação de metas de inflação e a concessão de plena liberdade aos dirigentes do banco central para alcançar o objetivo estabelecido. $\mathrm{E}$ autores keynesianos afirmam, grosso modo, que uma correta e responsável administração monetária, fiscal e cambial associada à instituição de regras claras são as âncoras de que o nível de preços necessita. Cabe ressaltar que as economias desenvolvidas que não aderiram ao regime de metas, também não possuem âncora cambial, mas todas têm mantido a inflação em níveis aceitáveis.

A decisão tomada pelo governo brasileiro foi, no mínimo, precipitada e, talvez, incorreta. Nenhum país, entre aqueles de economia desenvolvida, reduziu a inflação em razão da adoção de metas. Como foi mostrado, não há evidências de que conceder ao banco central a tarefa única de alcançar uma meta de inflação seja benéfico. O Federal Reserve System tem explicitamente dois objetivos, conter a inflação (sem qualquer meta fixada) e buscar o pleno emprego. E ninguém pode negar que os Estados Unidos foi o país que obteve mais sucessos econômicos na década de 1990. Em seu editorial (reproduzido na Gazeta Mercantil, 19/6/1999), o Financial Times afirmou:

Não é tarefa do Federal Reserve (Fed - o banco central dos EUA) esperar a inflação subir e só então aumentar a taxa de juros. Isso seria muito fácil. Sua tarefa é sustentar o crescimento, ao mesmo tempo em que mantém a inflação baixa, o que é muito mais difícil. [Mas] o Fed tem trabalhado bem. A expansão norte-americana dos anos 90 foi extraordinária.

Em suma, as evidências são, no mínimo, inconclusivas em relação à adoção do regime de metas. Ademais, existem controvérsias relevantes acerca da teoria que sustenta tal regime. Portanto, utilizá-lo principalmente em fases de desaquecimento da economia poderá deixar muitos governos sem um importante instrumento de combate ao desemprego.

\section{REFERÊNCIAS BIBLIOGRÁFICAS}

CARDIM DE CARVALHO, F. (1999). “Políticas Econômicas para Economias Monetárias”. In: Lima, G., Sicsú, J. \& De Paula, L. F. (orgs.), Macroeconomia Moderna: Keynes e a economia contemporânea. Rio de Janeiro: Editora Campus.

FRIEDMAN, M. (1987). “Should There Be an Independent Monetary Authority?”. In: The Essence of Friedman. Stanford: Hoover Institution Press.

HALDANE, A. (org.) (1995). Targeting Inflation. London: Bank of England.

HAHN, F. (1984). Equilibrium and Macroeconomics. Oxford: Basil Blackwell.

KEYNES, J. M. (1972). Essays in Persuasion. London: MacMillan.

KYDLAND, F. \& PRESCOTT, E. (1994). "Rules Rather Than Discretion: the Inconsistency of Optimal 
Plans”. In: Persson, T. \& Tabellini, G. (orgs.), Monetary and Fiscal Policy - vol. 1: Credibility. Cambridge (Mass): MIT.

MISHKIN, F. \& POSEN, A. (1997). “Inflation Targeting: Lessons from Four Countries”, Economic Policy Review, vol.3 (3), Federal Reserve Bank of New York.

PERSSON, T. \& TABELLINI, G. (orgs.) (1994). Monetary and Fiscal Policy - vol. 1: Credibility. Cambridge (Mass): MIT.

TOBIN, J. (1996). Essays in Economics: National and International. Cambridge (Mass): MIT.

Gráfico 1: Trajetória da Inflação na Nova Zelândia (1986-1998)

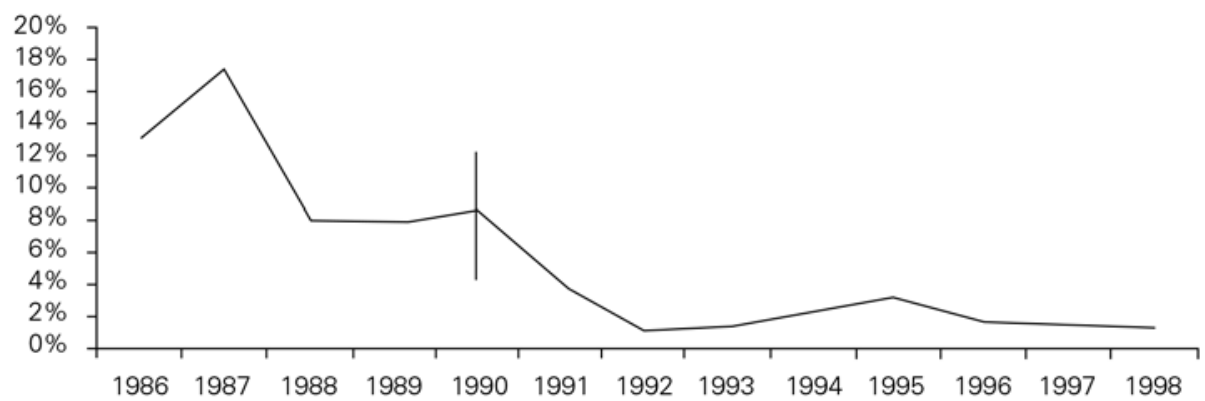

Gráfico 2: Trajetória da Inflação no Canadá (1986-1998)

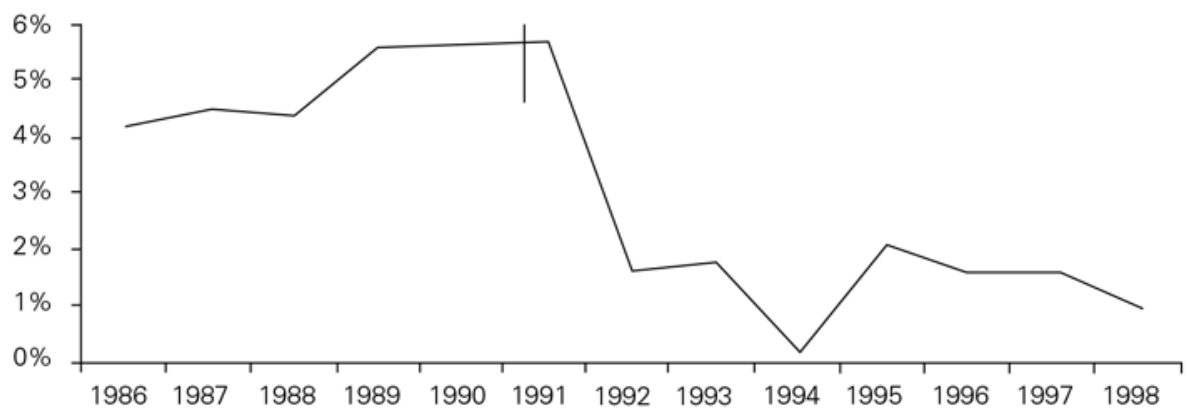

Gráfico 3: Trajetória da Inflação no Reino Unido (1986-1997)

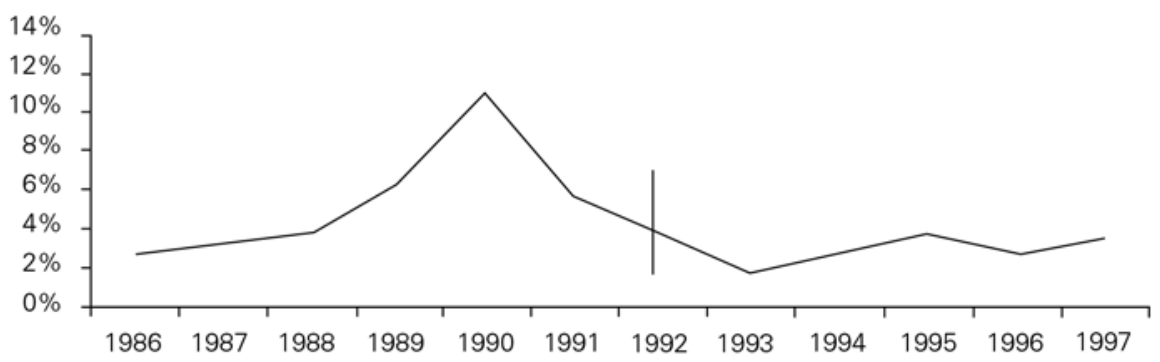


Gráfico 4: Trajetória da Inflação na Suécia (1986-1997)

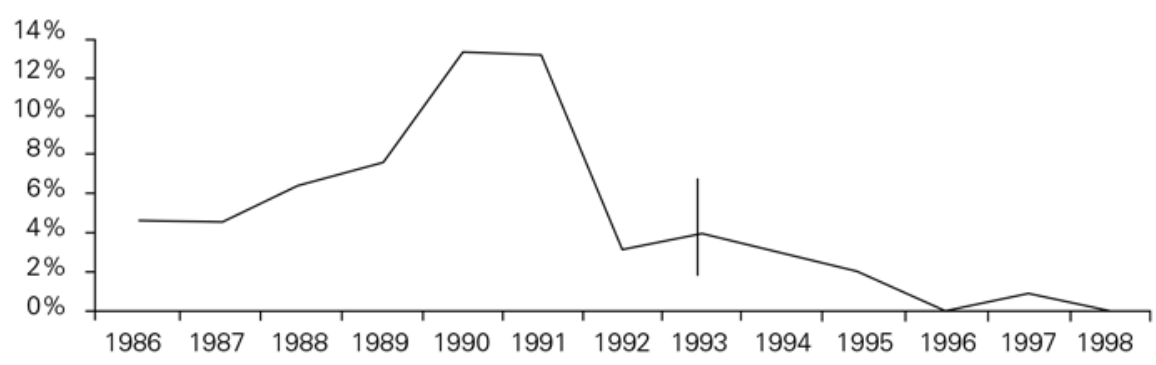

Gráfico 5: Trajetória da Inflação na Finlândia (1986-1998)

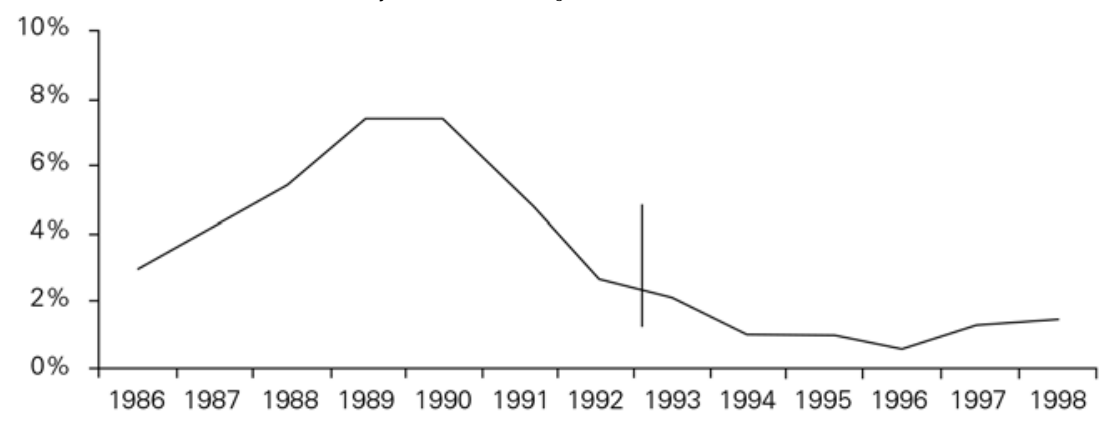

Gráfico 6: Trajetória da Inflação na Austrália (1986-1998)

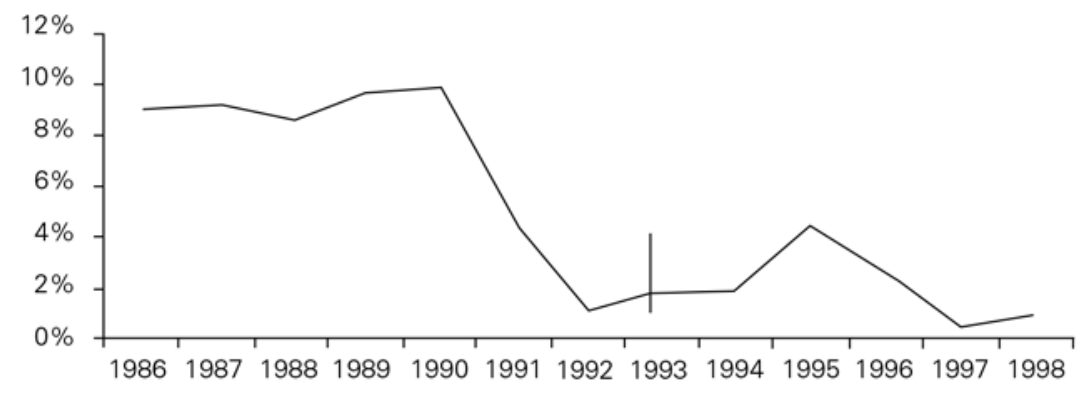

Gráfico 7: Trajetória da Inflação na Espanha (1986-1998)

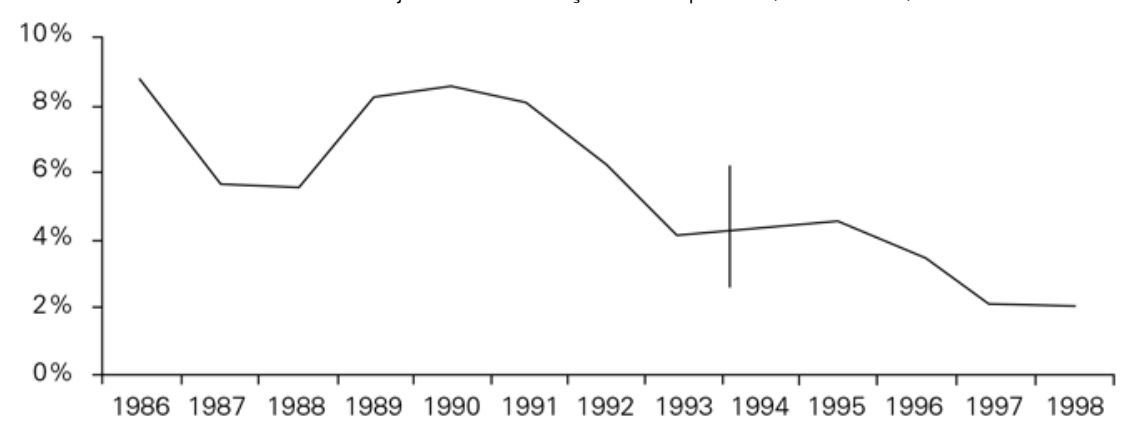


Gráfico 8: Inflação Média nos Países Desenvolvidos sem Metas de Inflação (1986-1998)

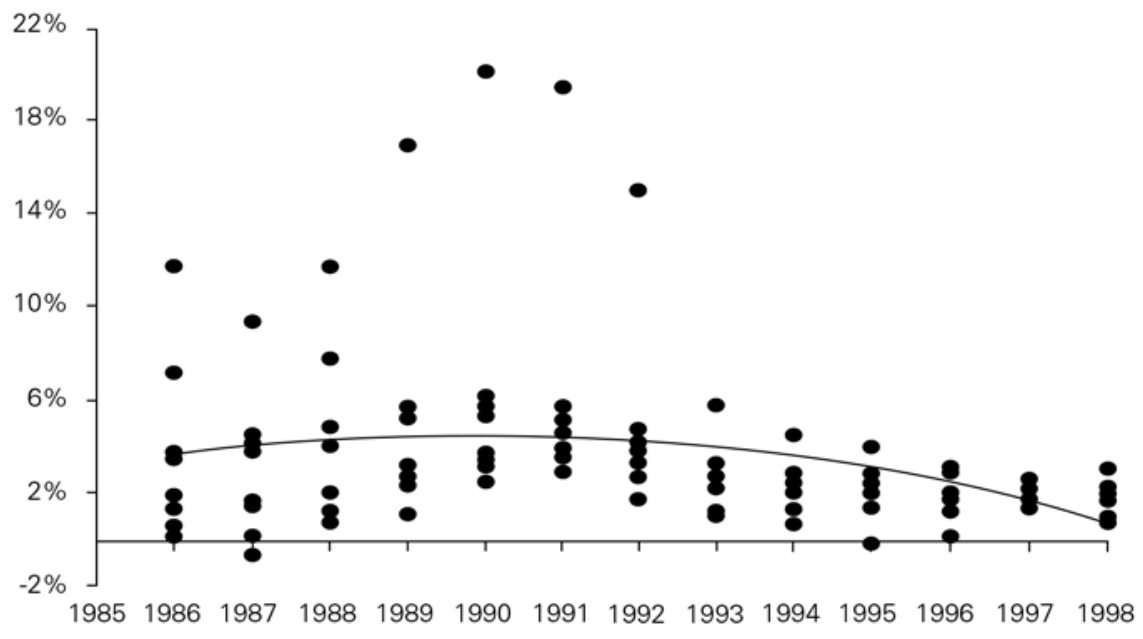

